\title{
ANÁLISE DAS FONTES DE CRESCIMENTO DO VALOR BRUTO DA PRODUÇÃO DA MAMONA NO PERÍODO DE 1990 A 2016
}

\author{
Renan Silva Ferreira* \\ André Souza Melo**
}

\begin{abstract}
RESUMO: Este trabalho tem como objetivo analisar o Valor Bruto da Produção agrícola da mamona para o Nordeste brasileiro, com resultados extensivos ao Estado da Bahia. Três variáveis foram testadas com respeito à contribuição para o crescimento da produção da mamona na região: área colhida, produtividade média e preço pago ao produtor. Nesse sentido, as análises das variáveis em termos evolutivos ao longo do tempo podem dar indicações do que se passa na atividade, de modo a se planejar melhores direcionamentos políticos no fortalecimento das fontes primordiais de crescimento. Neste estudo, optou-se pelo modelo matemático Shift-Share, cujos resultados são importantes indicadores para o planejamento dos atores envolvidos na produção da cultura da mamona. Como principal resultado, é impreciso indicar uma variável mais importante na explicação das flutuações do Valor Bruto de Produção no período entre 1990 e 2016. Contudo, as evidências são claras quando a análise se restringe a fases distintas no horizonte estudado, com maior influência por parte de um efeito-preço.
\end{abstract}

PALAVRAS-CHAVE: Mamona; Modelo Shift-Share; Valor bruto da produção.

\section{ANALYSIS OF GROWTH SOURCES OF THE GROSS VALUE OF CASTOR BEAN PRODUCTION BET WEEN 1990 AND 2016}

ABSTRACT: The gross production value of castor beans in northeastern Brazil is analyzed, coupled to results from the state of Bahia. Three variables were tested with regard to the contribution for the growth of castor bean production in the region: harvested area, mean productivity and price paid to the producer. Analysis of variables over time may indicate details on the activity so that better administration policies may be planned for the strengthening of growth sources. The mathematical model Shift-Share was employed, with important results for the planning of agents involved in the production of castor beans. Results reveal that it is impossible to pin-

Mestre em Administração e Desenvolvimento Rural pela Universidade Federal Rural de Pernambuco (UFRPE), Brasil. E-mail: renansilvaferreirax@gmail.com

* Doutor em Economia pela Universidade Federal Rural de Pernambuco (UFRPE), Brasil. 
point the most important variable for the fluctuations of the gross production value between 1990 and 2016. However, analysis limits itself to different phases with great influence by price.

KEY WORDS: Castor bean; Shift-Share model; Gross production value.

\section{INTRODUÇÃO}

O cultivo da mamona, também chamado de ricinocultura, é uma cultura explorada no Brasil há muito tempo em função do seu óleo extraído, que serve como matéria-prima para vários fins, como alimentação, química têxtil, papéis, plásticos, borrachas, perfumaria, cosméticos, farmácia, eletroeletrônicos, telecomunicações, tintas, adesivos, lubrificantes, etc. (AMORIM, 2005). Trata-se, pois, de uma planta oleaginosa de importância econômica e social.

Existe uma incerteza quanto à origem dessa cultura. Segundo Chierice e Claro Neto (2001), a procedência dessa planta é muito discutida, já que existem relatos de antigos cultivos na Ásia e na África, e a diversificação de um grande número de variedades da planta encontradas nesses dois continentes impossibilita saber a procedência efetiva da mamona. A facilidade de propagação e de adaptação em diferentes condições climáticas propiciou à mamona ser encontrada ou cultivada em várias regiões no mundo. No Brasil, a introdução dessa cultura foi realizada pelos portugueses no intuito de utilizar seu óleo para iluminação e lubrificação de carroças. O clima tropical facilitou seu alastramento, podendo-se encontrar a planta atualmente em quase toda a extensão territorial, como se a mesma fosse nativa, bem como em cultivos destinados à produção de óleo.

No Nordeste, a planta é encontrada em abundância, concentrando cerca de $90 \%$ da produção nacional, de acordo com o IBGE (BRASIL, 2017a). De acordo com a mesma fonte, o Estado da Bahia responde por $90 \%$ da produção do Nordeste, onde a mamona apresenta ampla vantagem competitiva na produção, com reduzidos custos produtivos e ótima adaptação e resistência às secas, tornando-se alternativa viável para a produção e de fácil manejo. Em outras regiões, porém, a mamona encontra forte concorrência frente a outras culturas mais rentáveis, con- 
forme esclarecem Kouri et al. (2004). Sem embargo, para o Nordeste, é justamente a inexistência de uma variedade de culturas concorrentes que retarda a adoção de novas tecnologias para a mamona na região.

A força de trabalho da própria família explora pequenas áreas sempre sob o modelo de triconsórcio (feijão, milho e mamona). A mamona assume papel social de grande relevância, assegurando uma contínua fonte de renda para as despesas da casa. Este sistema é pouco mecanizado, os agricultores utilizam sementes comuns e não usam insumos modernos, como adubos e agrotóxicos (BAHIA, 1995, p. 12).

Quanto à utilização dos produtos da planta, um uso relevante de seu óleo está na produção do biodiesel da mamona, que é uma alternativa ao diesel comum especialmente por diminuir as emissões, durante a combustão, de gases $\mathrm{CO}_{2}$ (dióxido de carbono) e SOx (óxido de enxofre), além de partículas de hidrocarbonetos, quando comparado aos combustíveis fósseis (ALMEIDA et al., 2004). Atualmente, as discussões a respeito de fontes alternativas de energia, sejam elas etanol, gás natural e biodiesel, têm ultrapassado as questões meramente energéticas e se estendido para a preocupação com meio ambiente e questões de fundo econômico como a inclusão social. Ponchio (2004) argumenta que o quadro de problemas tende a melhorar, pois assegurada a comercialização, a estruturação do agronegócio passa a ser facilitada. Atrelado à preocupação ambiental e social, existem diversos lançamentos de programas, no âmbito de diferentes esferas governamentais, visando aperfeiçoar e incentivar a produção de biodiesel no Brasil, priorizando oleaginosas que propiciem maior emprego de mão de obra e insiram regiões que estejam à margem do processo de desenvolvimento econômico do país. Nesse caso a mamona é uma excelente alternativa principalmente para a região Nordeste.

Apesar de sua elevada importância de cunho social, o cultivo da mamona sofre diversos problemas na região, além da já conhecida deficiência tecnológica. Segundo Ponchio (2004), apesar de existirem diversos estudos sobre a produção de mamona e seu ciclo de exploração econômica, a cadeia produtiva da mamona ainda 
não está devidamente organizada, devido aos oscilantes volumes de produção ao longo do tempo, que acompanham as oscilações de preço e as inconstantes políticas de incentivos. Vieira et al. (1997) ainda citam outros problemas, como os baixos preços oferecidos aos produtores, a reduzida oferta de crédito, a utilização da mesma área para sucessivos plantios da cultura, a desorganização e a inadequação dos sistemas de produção vigentes, bem como a desorganização no mercado interno, tanto para o produtor como para o consumidor final.

Os problemas citados têm origem em uma problemática bastante complexa, envolvendo um leque de fatores, os quais necessitam serem mais bem compreendidos para que a situação possa ser visualizada com maior transparência e assim buscar alternativas mais eficazes no sentido de minimizar seus efeitos negativos. Isso permite ações dos planejadores na concessão do crédito rural (bancos), dos produtores (pela tomada de decisão em investir) e mesmo das flutuações do mercado (oferta e demanda) deste produto. Nesse contexto, objetiva-se nesse trabalho determinar o Valor Bruto da Produção da mamona nordestina, de 1990 a 2016, e verificar em que nível as componentes área colhida, produtividade média e preço influenciaram no seu acréscimo ou no seu declínio. Tendo em vista que $90 \%$ da produção nordestina advêm da Bahia, os resultados a serem encontrados são extensivos a esse Estado, bem como podem se estender ao Brasil, visto que $90 \%$ da produção nacional advêm do Nordeste (BRASIL, 2010a).

Além desta introdução, o presente estudo conta com uma revisão da literatura, que além de expor características históricas da cadeia produtiva, bem como dos mercados externo e interno da mamona, destaca as relações entre sua produção e o Programa de Biodiesel do Governo Federal. Posteriormente, são apresentados os materiais e métodos aplicados na pesquisa, com ênfase na discussão do Modelo Shift-Share. Os resultados são discutidos na sequência, detalhando-se o comportamento das séries analisadas, bem como a aplicação do Modelo Shift-Share para a verificação das fontes de variação do Valor Bruto da Produção da mamona. Por fim, são apresentadas as principais conclusões do estudo. 


\section{REVISÃO DA LITERATURA}

\subsection{ASPECTOS HISTÓRICOS, CADEIA PRODUTIVA, MERCADOS EXTERNO E INTER- NO DA MAMONA}

Como comentado, a mamona é uma oleaginosa que tem utilidade de sua matéria-prima para vários fins. Sua origem é anunciada como incerta; Chierice e Claro Neto (2001) dizem que uns acreditam que ela se originou na África e outros na Ásia, o que se deve ao fato da existência de um grande número de variedades da planta, impossibilitando a determinação exata de sua origem. No Brasil, segundo estudos de Kouri et al. (2004), Freitas e Fredo (2005), Amorim (2005) e Pires (2004), a planta chegou com os portugueses no período colonial. Nessa época, segundo esses autores, o óleo de rícino era utilizado para geração de luz (energia) e para fins medicinais (purgativo e unguento para as moléstias das articulações, inflamações em geral, dor de ouvido e assaduras). No século XX, especificamente nas décadas de 1970 e 1980, a mamona, assim como outras fontes renováveis de energia, ganhou destaque na utilização como substituto dos derivados de petróleo. A partir de estudos, foi descoberto que a mamona também é responsável pela produção de vários produtos nos setores de alimentação, química têxtil, papéis, plásticos, borrachas, perfumaria, cosméticos, farmácia, eletroeletrônicos, telecomunicações, tintas, adesivos, lubrificantes para aviões e naves espaciais, vidros à prova de balas, cabos de fibra ótica, lentes de contato, etc. Nos últimos anos, o óleo de mamona também tem sido utilizado na medicina para a fabricação de cimento ósseo e próteses do corpo humano. Na geração de energia, por sua vez, o óleo de mamona torna-se propício a fazer frente à produção de biodiesel.

No que tange à cadeia produtiva da mamona, Amorim (2005) destaca que os agentes pré e pós-colheita interagem da seguinte forma: os produtores de mamona fornecem o produto para a indústria processadora e para os atravessadores; estes que recebem o produto, também fornecem para a indústria de processamento. Desta indústria, a matéria-prima é fornecida para o mercado externo e também para a indústria química, para a produção de têxteis, plásticos, etc. De acordo com

3 Este autor apresentou um estudo mais completo sobre cadeia produtiva, mercado externo, mercado interno e comercialização da mamona. Por esse motivo, será bastante citado na presente revisão bibliográfica. 
informações da EMBRAPA (BRASIL, 2010b), a industrialização da mamona tem como principal produto o óleo; e, como subproduto, obtém-se a torta, que se trata de um fertilizante que possui a capacidade de restauração de terras esgotadas, com alto teor de proteínas - entretanto, ela é muito tóxica, servindo apenas para alimentação animal se passar por um caro processo de desintoxicação que inviabiliza para o consumo, servindo apenas para fins agrícolas.

Quanto à produção mundial, segundo dados da Food and Agriculture Organization of the United Nations (FAO, 2010), o Brasil obtinha o título de maior produtor mundial de mamona durante as décadas de 1960, 1970 e até o final da década de 1980. A partir de então, o mercado passou a ser dominado pela Índia e pela China. Segundo Amorim (2005), no que se refere à comercialização entre países, a mamona no seu estado primário foi comercializada na fase áurea do mercado externo, justamente quando o Brasil foi o líder da produção mundial de mamona. A partir da década de 1980, entretanto, houve uma tendência de extinção da exportação da mamona em grãos. Esta fase coincide com a decadência da produção no Brasil e com o advento da Índia como principal produtor. Quanto ao óleo de mamona, o Brasil também liderou o mercado mundial até a década de 1980. A primeira grande queda nas exportações brasileiras ocorreu no início dessa década, justamente quando se deu o início do grande aumento das exportações indianas. A Índia passou a dominar a comercialização de óleo de mamona a partir do final dos anos 1980, e caracteriza-se até o presente como o principal exportador mundial. Segundo a FAO (2010), o Brasil ficou em $10^{\circ}$ colocado no ranking mundial das exportações de óleo de mamona, no ano de 2007, com um total de 746 toneladas exportadas; enquanto a Índia exportou, no mesmo ano, algo em torno de 250 mil toneladas. Seguindo a Índia, os maiores exportadores mundiais no ano de 2007 foram Países Baixos (28,6 mil toneladas), França (15,3 mil toneladas), Alemanha (5,2 mil toneladas) e Estados Unidos (3,8 mil toneladas).

Quanto ao mercado nacional, de acordo com Coelho (1979), a mamona se desenvolveu nas regiões Sudeste, Sul e Nordeste do Brasil. Nas regiões Sudeste e Sul, para se garantir a competitividade da mamona frente à forte concorrência com outras culturas, investiu-se na mecanização das técnicas produtivas, o que levou ao desenvolvimento de variedades mais rentáveis. "Deste modo, tornou-se possível 
cultivar variedades anãs e indeiscentes, cuja maturação ocorre aproximadamente ao mesmo tempo em todas as bagas. Isto permite colheita mecânica única anual" (BIODIESELBR, 2010, web). No Nordeste, a produção é pouco mecanizada, segundo Kouri et al. (2004) e Amorim (2005), o que decorre da baixa concorrência da mamona com outras culturas e da instabilidade climática. Ainda que atrasada tecnologicamente, a região se caracteriza como o maior produtor de mamona no Brasil, com cerca de $90 \%$ da produção nacional, de acordo com o IBGE (BRASIL, 2010a). $\mathrm{Na}$ região, segundo a mesma fonte, o principal Estado produtor é a Bahia, respondendo por cerca de $90 \%$ da produção do Nordeste brasileiro.

A mamona no Nordeste também representa um importante marco no aspecto socioeconômico. A produção é ligada à agricultura familiar, que utiliza a mão de obra da região e produz apenas em pequenas áreas, com carência na utilização de tecnologias avançadas e insumos modernos por parte dos agricultores. A mamona tem papel relevante na renda do agricultor do Nordeste para as despesas da casa (BAHIA, 1995). Freitas e Fredo (2005) argumentam ainda que a ricinocultura é capaz de se engajar no Programa Fome Zero do Governo Federal. Segundo esses autores, "a importância da mamona para este programa, deriva-se do próprio sistema de produção da mamona que praticado por pequenos produtores, é intensivo em mão-de-obra (gera empregos) e pode ser feito em consórcio e/ou rotação com outras culturas, aumentando não só a renda do agricultor por hectare, como também o volume de alimentos por área” (FREITAS; FREDO, 2005, p. 37).

\subsection{MAMONA E BIODIESEL}

Além do Programa Fome Zero, no qual a importância da mamona se dá pelo seu próprio sistema produtivo que é associado à agricultura familiar, Freitas e Fredo (2005) indicam que a ricinocultura também é capaz de se engajar amplamente no Programa Nacional de Biodiesel, que além da inclusão social, almeja reduzir tanto as importações de petrodiesel quanto a queima de combustíveis fósseis. Nesse sentido, destaca-se que além das vantagens socioeconômicas que a cultura da mamona propicia, essa oleaginosa apresenta teor de óleo acima das demais, além do que cada hectare cultivado com mamona absorve dez toneladas de gás carbônico. Apesar das 
vantagens socioeconômicas, os autores tiveram como resultado de seu trabalho que a produtividade do óleo da mamona não se expressa tanto na região Nordeste em alguns territórios ou momentos, e que o fomento da ricinocultura deve ser acompanhado de investimentos em pesquisas agronômicas. Obstáculos de natureza técnica e econômica também devem ser superados de modo a viabilizar o biodiesel à base de óleo de mamona na matriz energética brasileira.

Almeida et al. (2004) apresentam um estudo prospectivo da produção nacional de biodiesel de mamona e determinam o nível de investimento público necessário para atingir as metas iniciais de produção propostas ${ }^{4}$. Para substituir $2 \%$ do consumo interno de diesel, serão necessários 786 milhões de litros de biodiesel, com base no consumo em 2003. Deste volume, 293 milhões de litros (40\%) deverão ser obtidos a partir do óleo de mamona, com investimento na ordem de $\mathrm{R} \$ 370 \mathrm{mi}$ lhões. Constatou-se uma ociosidade de $71 \%$ na indústria de esmagamento de óleo de mamona. Porém, esse setor opera com lucratividade em função do preço do óleo da mamona. Ademais, foi identificado um déficit de 55\% na área plantada de mamona destinada exclusivamente para a produção de biodiesel. Cabe ressaltar ainda que, a partir de 2013, o percentual mínimo obrigatório de adição de biodiesel ao óleo diesel comercializado ao consumidor final será de 5\%, conforme a Lei no 11.097 (BRASIL, 2005), o que eleva ainda mais a necessidade de se investir na produção de óleo de mamona.

Pires et al. (2004), que estudaram a viabilidade econômica da produção de mamona para o biodiesel, concluíram também que a produção de óleo de mamona apresenta-se estagnada. No entanto, em função dos incentivos previstos para mamona, prevê-se um crescimento da cultura. Quanto à formação dos preços no mercado, devem-se levar em conta alguns fatores relativos ao custo de produção da mamona e do óleo, à incidência de impostos e à escala de produção. Eles chamam atenção que a produção de óleo de mamona é economicamente viável; porém, são necessárias políticas de incentivo para o aumento da oferta de mamona no mercado, que atualmente se encontra abaixo da demanda.

A importância das políticas é fator extremamente relevante para o desenvol-

$\overline{4}$ De acordo com a Lei no 11.097 (BRASIL, 2005), que dispõe sobre a introdução do biodiesel na matriz energética brasileira, estipulouse que, a partir de 2008 , o percentual mínimo de adição de biodiesel ao diesel mineral deve ser equivalente a $2 \%$, em caráter autorizativo. 
vimento da produção de mamona no semi-árido nordestino, principalmente para os pequenos agricultores. Para Park (2006), no projeto de biodiesel, os agricultores de propriedade familiar enfrentam sérios problemas e limitações que se dividem em fatores externos e internos. Os problemas externos são aqueles gerados fora da propriedade agrícola e da comunidade, ou seja, são aqueles que não dependem do agricultor: ausências de políticas agrícolas claras e estáveis, com destaque para preços mínimos do produto, assistência técnica e extensão rural, crédito e pesquisas agrícolas, bem como a falta de incentivos na aquisição de bens de capital. Os problemas internos, por sua vez, são os que se originam dentro das propriedades e comunidades, cuja solução está ao alcance do agricultor. Dentre esses problemas, destacam-se a não utilização de cultivares melhoradas de alta produtividade, a ausência de informações e orientações que possibilitem a formações de cooperativas, além do pouco conhecimento e falta de incentivos que possibilitem a melhoria na qualidade do produto.

A maioria dos pequenos agricultores vive em condição de sobrevivência e o lado econômico é o principal fator de estímulo ao potencial cultivador de plantas oleaginosas como a mamona. Assim, segundo Park (2006), o agente interessado na cadeia de biodiesel deverá trabalhar com essas limitações, pensando na alternativa de reger um contrato comercial de trabalho com esses cultivadores caso deseje conquistar o "selo social" do biodiesel.

Nesse sentido, a mamona surge como uma cultura temporária de alto destaque, sendo considerada em muitos trabalhos como a principal fonte de óleo para a produção de biodiesel no Brasil, sendo considerada atualmente a cultura de sequeiro mais rentável em certas áreas do semi-árido nordestino (CHIARANDA et al., 2005).

\section{METODOLOGIA}

\subsection{ORIGEM DOS DADOS}

O valor bruto de produção (medido em Reais) foi decomposto em três va- 
riáveis: área colhida pelo produtor de mamona em bagas, rendimento médio da produção (ou produtividade média) e preço pago ao produtor. A área colhida é medida em hectares; o rendimento médio da produção, que indica a produtividade do cultivo da mamona, é medido em quilogramas por hectare; e o preço pago ao produtor, em Reais por quilograma do produto, foi calculado dividindo-se a quantidade produzida pelo valor produzido. O período de análise estudado foram os anos de 1990 a 2016. Na Tabela 1, observam-se os dados utilizados na análise, que tiveram origem na Pesquisa Agrícola Municipal dos anos de 1990 a 2016, realizada pelo IBGE (BRASIL, 2010a).

Tabela 1. Origem dos dados para analisar a evolução do Valor Bruto de Produção da mamona: Nordeste, 1990-2016

(Continua)

\begin{tabular}{ccccc}
\hline Ano & $\begin{array}{c}\text { Valor Bruto da } \\
\text { Produção }(\mathbf{R} \$)\end{array}$ & Área Colhida (ha) & $\begin{array}{c}\text { Produtividade } \\
\text { Média (kg/ha) }\end{array}$ & Preço (R\$/kg) \\
\hline 1990 & 700,96 & $267.581,00$ & 461,27 & 0,00001 \\
1991 & $4.542,88$ & $217.937,00$ & 511,29 & 0,00004 \\
1992 & $23.080,41$ & $164.872,00$ & 543,12 & 0,00026 \\
1993 & $288.935,64$ & $135.286,00$ & 264,62 & 0,00807 \\
1994 & $9.148 .000,00$ & $103.483,00$ & 487,28 & 0,18142 \\
1995 & $6.427 .000,00$ & $73.587,00$ & 401,12 & 0,21774 \\
1996 & $9.681 .000,00$ & $118.272,00$ & 334,04 & 0,24504 \\
1997 & $20.878 .000,00$ & $149.943,00$ & 625,40 & 0,22264 \\
1998 & $3.471 .000,00$ & $60.267,00$ & 218,11 & 0,26405 \\
1999 & $10.574 .000,00$ & $99.240,00$ & 283,23 & 0,37619 \\
2000 & $32.616 .000,00$ & $177.367,00$ & 492,57 & 0,37333 \\
2001 & $27.952 .000,00$ & $151.613,00$ & 483,92 & 0,38098 \\
2002 & $33.225 .000,00$ & $113.402,00$ & 590,96 & 0,49578 \\
2003 & $65.145 .000,00$ & $128.029,00$ & 591,03 & 0,86092 \\
2004 & $128.665 .000,00$ & $163.994,00$ & 772,36 & 1,01581 \\
2005 & $86.447 .000,00$ & $219.732,00$ & 700,94 & 0,56128 \\
2006 & $49.444 .000,00$ & $138.497,00$ & 601,31 & 0,59371 \\
2007 & $65.243 .000,00$ & $151.821,00$ & 552,10 & 0,77837 \\
2008 & $92.212 .000,00$ & $148.074,00$ & 731,60 & 523121 \\
2009 & $60.447 .000,00$ & $150.478,00$ & & \\
\hline & & & & 0,28055 \\
\hline
\end{tabular}


(Conclusão)

\begin{tabular}{ccccc}
\hline Ano & $\begin{array}{c}\text { Valor Bruto da } \\
\text { Produção }(\mathbf{R} \$)\end{array}$ & Área Colhida (ha) & $\begin{array}{c}\text { Produtividade } \\
\text { Média }(\mathbf{k g} / \mathbf{h a})\end{array}$ & Preço $(\mathbf{R} \mathbf{\beta} / \mathbf{k g})$ \\
\hline 2010 & $78.520 .000,00$ & $141.250,00$ & 589,00 & 0,94331 \\
2011 & $112.092 .000,00$ & $208.476,00$ & 576,00 & 0,93280 \\
2012 & $24.058 .000,00$ & $84.390,00$ & 308,00 & 0,92569 \\
2013 & $17.830 .000,00$ & $43.635,00$ & 287,00 & 1,42343 \\
2014 & $48.359 .000,00$ & $61.005,00$ & 576,00 & 1,37555 \\
2015 & $66.740 .000,00$ & $81.768,00$ & 565,00 & 1,44521 \\
2016 & $22.096 .000,00$ & $40.115,00$ & 551,00 & 0,55081 \\
\hline
\end{tabular}

Fonte: Elaboração própria, com base na Pesquisa Agrícola Municipal do IBGE (BRASIL, 2017a).

\subsection{MODELO SHIFT-SHARE}

Para o presente estudo, optou-se pela utilização do modelo matemático Shift-Share, cujos resultados podem significar importantes indicadores para o planejamento dos atores envolvidos na produção da cultura da mamona. Na literatura, não foi encontrada a aplicação dessa metodologia exclusivamente para o cultivo da mamona, com exceção dos estudos de Albuquerque e Pinheiro (1980) e Souza e Lima $(2002)^{5}$. O modelo matemático foi aplicado na produção de cacau por Filgueiras et al. (2003) e na produção de pimenta do reino por Filgueiras et al. (2002), ambos para o Estado do Pará. Além desses autores, Magrini e Canever (2003) fizeram a mesma aplicação de modelo para a produção de arroz no Estado do Rio Grande do Sul.

No presente estudo, o Modelo Shift-Share, também denominado Modelo Diferencial-Estrutural, foi utilizado como uma adaptação para a decomposição da taxa de crescimento do valor da produção da mamona de 1990 a 2016 nas componentes área colhida, produtividade média e preço pago ao produtor, estimando-se a importância relativa de cada um dos componentes sobre os acréscimos ou decréscimos do Valor Bruto da Produção da mamona. Considera-se, portanto, que a variação na produção da mamona, assim como os demais bens agrícolas, deve-se não só a fatores edafoclimáticos (refletidos na produtividade), mas também devem ser consi-

\footnotetext{
Ambos fizeram estudos para a agricultura desagregada, sendo a mamona apenas um dos setores analisados.
} 
deradas as variáveis econômicas, como preço e demanda. Esse modelo tem sido utilizado em vários campos do conhecimento econômico, destacando-se os trabalhos de Yokoyama e Igreja (1992), com um estudo sobre as componentes das variações na quantidade produzida das principais lavouras do Centro-Oeste entre 1975 e 1987; e, mais recentemente, o estudo de Araújo e Campos (1998), que também utilizaram esse método para analisar a evolução do valor da produção de cacau no Estado da Bahia.

Formalmente, o modelo mede a variação entre dois pontos, sendo o período inicial denominado "período zero" e o período final denominado "período t". Assim, no período inicial (0), o Valor Bruto da Produção $\left(V_{0}\right)$ é o produto da área colhida $\left(A_{0}\right)$, da produtividade ou rendimento médio $\left(R_{0}\right)$ e do preço pago ao produtor $\left(P_{0}\right)$, como definido a seguir:

$$
V_{0}=A_{0} \cdot R_{0} \cdot P_{0}
$$

No período final $(t)$, por sua vez, o Valor Bruto da Produção $(V)$ é expresso como:

$$
V_{t}=A_{t} \cdot R_{t} \cdot P_{t}
$$

Como variáveis no presente estudo, define-se que: i) $V$ é o Valor Bruto da Produção da mamona (em Reais); ii) $A$ é a área colhida de mamona em bagas (em hectares); iii) $R$ é o rendimento ou a produtividade média da mamona (em quilogramas por hectare); e iv) $P$ é o preço pago ao produtor da mamona (em Reais por quilograma).

Para se verificar os efeitos de cada variável, é necessário efetuar isolamentos. Um primeiro diz respeito à variação ocorrida somente na área (no período $t$ ), permanecendo as demais componentes fixas no período zero. Nesse sentido, toma-se a variável $V^{A}$, em que:

$$
V_{t}^{A}=A_{t} \cdot R_{0} \cdot P_{0}
$$


Analogamente, a variável $V^{A, R}$ varia a área e o rendimento (produtividade), mantendo-se os preços constantes no período zero. Assim:

$$
V_{t}^{A, R}=A_{t} \cdot R_{t} \cdot P_{0}
$$

Importante verificar que a variação absoluta do Valor Bruto da Produção da mamona entre dois períodos $(t)$ e $(0)$ pode ser expressa da seguinte maneira:

$$
V_{t}-V_{0}=\left(A_{t} \cdot R_{t} \cdot P_{t}\right)-\left(A_{0} \cdot R_{0} \cdot P_{0}\right)
$$

A expressão acima pode ser escrita de outra maneira, tendo resultados equivalentes:

$$
V_{t}-V_{0}=\left(V_{t}^{A}-V_{0}\right)+\left(V_{t}^{A, R}-V_{t}^{A}\right)+\left(V_{t}-V_{t}^{A, R}\right)
$$

Através da expressão (6), é possível perceber a desagregação dos efeitos da variação absoluta no Valor Bruto da Produção, ou seja:

i) O termo $\left(V_{t}-V_{0}\right)$ diz respeito à variação total no Valor Bruto da Produção da mamona;

ii) O termo $\left(V_{t}^{A}-V_{0}\right)$ é o efeito-área, ou seja, a variação no Valor Bruto da Produção da mamona associada à variação de sua área colhida no mesmo horizonte de tempo;

iii) O termo $\left(V_{t}^{A, R}-V_{t}^{A}\right)$ é o efeito-rendimento, ou seja, a variação no Valor Bruto da Produção da mamona associada à variação de seu rendimento médio de cultivo (produtividade) no mesmo horizonte de tempo;

iv) O termo $\left(V_{t}-V_{t}^{A, R}\right)$ é o efeito-preço, ou seja, a variação no Valor Bruto da Produção da mamona associada à variação do preço pago ao produtor no mesmo horizonte de tempo;

Tais efeitos podem ser ainda apresentados em taxas anuais de crescimento (TAC). Para tanto, basta se utilizar da expressão (6) e dividir ambos os lados por ( $\left.V_{t}-V_{0}\right)$, ou seja: 


$$
1=\frac{\left(V_{t}^{A}-V_{0}\right)}{V_{t}-V_{0}}+\frac{\left(V_{t}^{A, R}-V_{t}^{A}\right)}{V_{t}-V_{0}}+\frac{\left(V_{t}-V_{t}^{A, R}\right)}{V_{t}-V_{0}}
$$

Posteriormente, determina-se uma taxa de crescimento entre dois períodos, que no presente estudo será representada por uma taxa anual de crescimento do período (0) para o período $(t)$, em valores percentuais:

$$
r=\left(\sqrt[t]{\frac{V_{t}}{V_{0}}}-1\right) \cdot 100
$$

Por fim, sendo $r$ a taxa anual de crescimento entre o período (0) e o período $(t)$, em valores percentuais, basta multiplicar ambos os lados da expressão (7) pela taxa $r$, encontrando-se assim os efeitos área, rendimento e preço em termos de percentagem:

$$
r=\frac{\left(V_{t}^{A}-V_{0}\right)}{V_{t}-V_{0}} r+\frac{\left(V_{t}^{A, R}-V_{t}^{A}\right)}{V_{t}-V_{0}} r+\frac{\left(V_{t}-V_{t}^{A, R}\right)}{V_{t}-V_{0}} r
$$

Importante verificar que a multiplicação da taxa $r$ não altera os resultados obtidos pela expressão fundamental do Modelo Shift-Share, ou seja, a expressão (6). Nesse sentido, a expressão (9) nada mais traz do que os efeitos desagregados em termos percentuais.

No presente estudo foram realizados dois tipos de análise sob o Modelo Shift-Share. Uma primeira teve características dinâmicas, com o objetivo de verificar as fontes de crescimento ou decréscimo do Valor Bruto da Produção da mamona em cada ano, entre 1990 e 2016. Por exemplo, deseja-se apontar qual a principal fonte do veemente crescimento entre os anos de 2003 e 2004, quando o Valor Bruto da Produção cresceu em $97,5 \%$. Por outro lado, também deseja-se verificar qual a principal fonte do forte decréscimo verificado entre os anos de 2005 e 2006, quando o Valor Bruto da Produção caiu cerca de 40\%, e também por exemplo, entre 2011 e 2012, onde houve outro decréscimo significativo com restabelecimento suavemente crescente até 2015 . Dessa maneira, essa primeira análise traz resultados ano a ano. Nesse sentido, no Modelo Shift-Share descrito, considerou-se o ano $(t-1)$ como o período (0). 
Por fim, uma última análise assume como período (0) aqueles anos em que ocorrem inícios de sequências de acréscimo ou decréscimos no Valor Bruto da Produção da mamona. Como observado na Tabela 1, apresentada anteriormente, consideram-se os seguintes períodos de análise: i) de 1990 a 1994, período em que ocorre forte acréscimo no Valor Bruto da Produção $\left(t_{0}=1990\right)$; ii) de 1995, ano em que a produção cai com relação a 1994, até 1997, quando ocorre uma nova fase de acréscimos $\left(t_{0}=1995\right)$; iii) de 1998 , ano em que se verifica queda com relação a 1997, até 2000, quando a mamona experimenta nova fase de expansão no seu Valor Bruto da Produção $\left(t_{0}=1998\right)$; iv) de 2001, quando se verifica leve queda com relação a 2000 , até o ano de 2004, período em que se verifica amplo crescimento $\left(t_{0}=2000\right)$; v) de 2004 a 2006, período em que se verifica forte queda $\left(t_{0}=2004\right)$; e vi) de 2006 até 2008, período em que o Valor Bruto da Produção volta a se elevar $\left(t_{0}=2006\right)$; vi) de 2008 a 2012, período em que se verifica um crescimento crescente, e uma significativa queda entre o ano 2011 e $2012\left(\mathrm{t}_{0}=2008\right)$; vii) de 2012 até 2016, período em que se verifica um aumento suave desde o $t_{0}=2012$ até 2015, sofrendo em 2016 um declínio. Nessa parte da análise, busca-se encontrar as fontes de crescimento ou decréscimo do Valor Bruto da Produção da mamona em cada fase descrita.

\section{RESULTADOS E DISCUSSÃO}

\subsection{COMPORTAMENTO DAS SÉRIES}

O período compreendido entre os anos de 1990 e 2016 é marcado por oscilações no Valor Bruto da Produção da mamona, como será apresentado mais adiante com maior detalhe. Inicialmente, é interessante observar o comportamento dos preços pagos ao produtor de mamona no horizonte de tempo estudado. Como apresentado na Figura 1, observam-se valores menores no início da década de 1990 até 1993; a partir de 1994, com o advento do Plano Real, o qual proporcionou melhorias para o produtor agrícola, verificou-se um aumento significativo no preço pago ao produtor de mamona. A explosão dos preços se verifica até o ano de 2004, quando foi implantado o ProBiodiesel do Governo Federal, o que acarretou uma elevação 
da demanda superior à oferta até então observada, o que implicou na brusca queda dos preços entre os anos de 2004 e 2005 . Nos anos seguintes, os preços pagos aos produtores de mamona voltaram a subir, em consonância com o paulatino ajuste de oferta. Em 2016, contempla um declínio significante no preço, decorrente da crise ocasionando falta de incentivos financeiros e inexistência de um preço mínimo para a comercialização no mercado nacional - e de condições climáticas adversas.

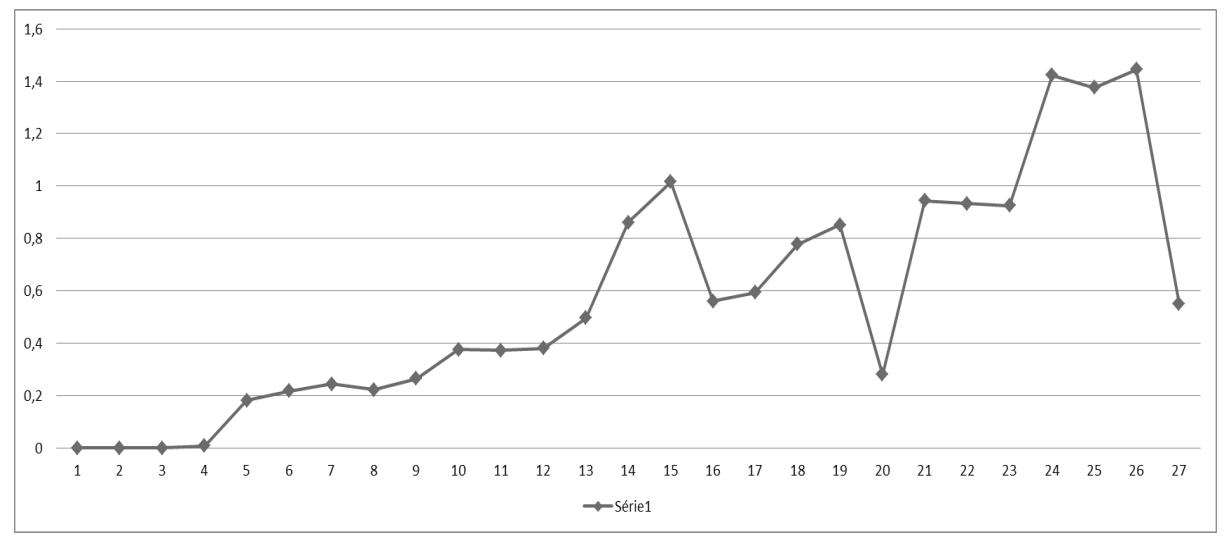

Figura 1. Evolução do preço pago ao produtor de mamona: Nordeste, 1990-2016 (R\$/kg). Fonte: Pesquisa Agrícola Municipal do IBGE (BRASIL, 2010a).

Com relação à área colhida e à quantidade produzida de mamona, constata-se uma movimentação caracterizada por fortes oscilações, conforme apresentado nas Figuras 2 e 3. Em certo grau, esse comportamento se mostra parcialmente coerente com os ditames das flutuações do preço. Isso se deve à possibilidade de arbitragem do produtor quanto à cultura a ser explorada em sua propriedade, tendo em vista que a mamona se caracteriza como um cultivo de ciclo curto ${ }^{6}$. Nesse sentido, é esperado que quedas ou mesmo estabilizações verificadas no preço, de um ano para o outro, reflitam em queda da produção no ano seguinte. Cabe ainda destacar que outros fatores também refletem na instabilidade da produção, como variações climáticas e disseminação de pragas e doenças.

$\overline{6} \quad$ Isso se verifica principalmente para variedades anãs. Vale salientar que, para as demais variedades, o ato de podar as plantas é capaz de evitar o replantio para uma safra posterior. Entretanto, não se recomenda podas sucessivas. 


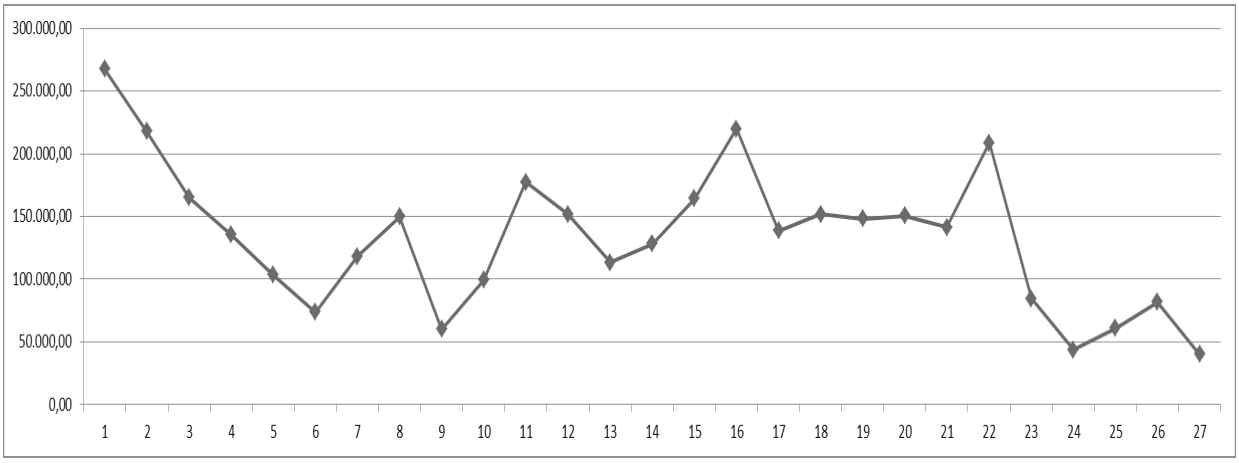

Figura 2. Evolução da área colhida de mamona: Nordeste, 1990-2016 (ha).

Fonte: Pesquisa Agrícola Municipal do IBGE (BRASIL, 2010a).

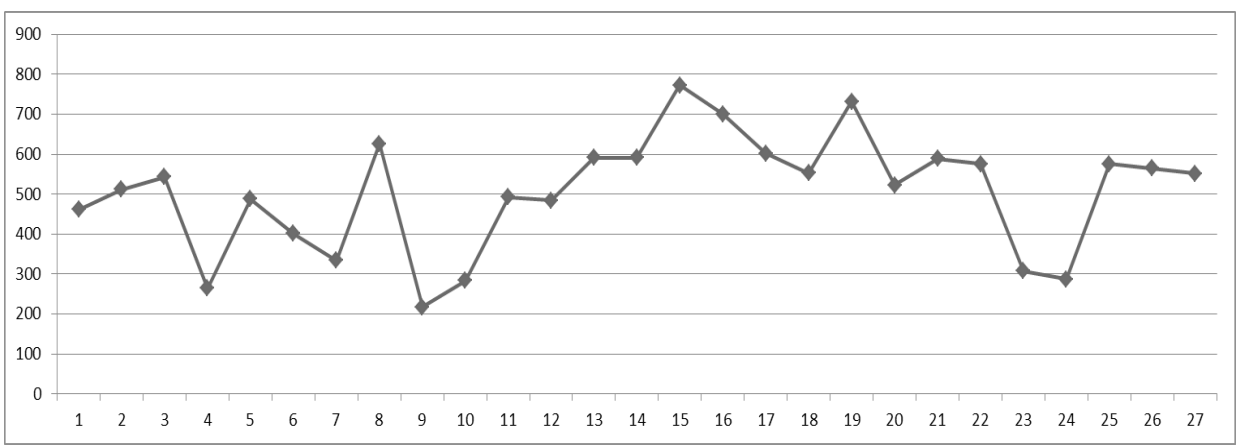

Figura 3. Evolução da quantidade produzida de mamona: Nordeste, 1990-2016 (ton).

Fonte: Pesquisa Agrícola Municipal do IBGE (BRASIL, 2010a).

Importante verificar que apesar das fortes oscilações na produção de mamona, é possível observar uma leve tendência decrescente na área colhida, quando se observa todo o horizonte de tempo. Tendo em vista que isso não é verificado claramente para a quantidade produzida, espera-se que ocorra uma tendência de sensível crescimento da produtividade. Nesse aspecto, conforme apresentado na Figura 4, pode-se observar que houve de fato um comportamento ascendente ao longo do período de análise. Conforme a equação linear meramente ilustrativa existe uma produção média de $354,9 \mathrm{~kg} / \mathrm{ha}$ independentemente do comportamento da estrutura ou manejo do cultivo durante o período. Mais ainda, a cada ano, verificou-se um acréscimo médio de $15,3 \mathrm{~kg} / \mathrm{ha}$, sinal da melhoria de características associadas à mão de obra, aos tratos culturais e/ou à qualidade e uso de insumos. Faz-se necessário, 
portanto, que órgãos de pesquisa e assistência técnica estejam preparados para melhor atender os produtores na condução de seus cultivos de mamona, incentivando-os na adoção de tecnologias adequadas.

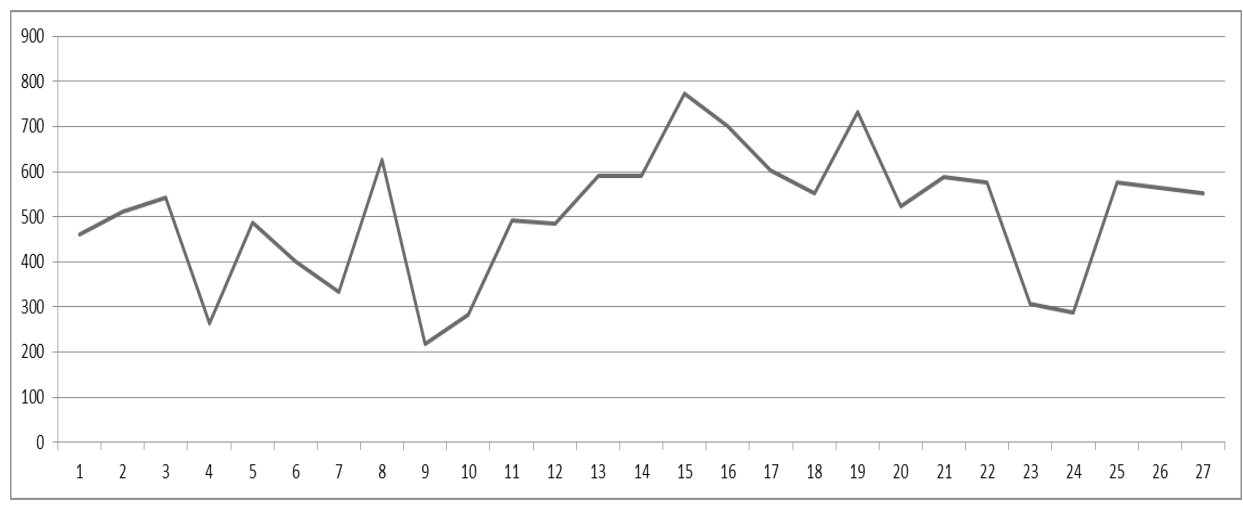

Figura 4. Produtividade ou rendimento médio na produção de mamona: Nordeste, 1990$2016(\mathrm{~kg} / \mathrm{ha})$.

Fonte: Pesquisa Agrícola Municipal do IBGE (BRASIL, 2010a).

Conforme apresentado, é patente que o período compreendido entre os anos de 1990 e 2016 foi marcado por oscilações no Valor Bruto da Produção da mamona, visto que deve refletir as oscilações observadas nas variáveis aqui destacadas: preços, área colhida e produtividade. Na Figura 5, verifica-se o comportamento apresentado pelo Valor Bruto da Produção da mamona, calculado como o produto entre a área colhida, a produtividade média e o preço pago ao produtor. Nesse aspecto, observam-se valores reduzidos entre 1990 e 1993, com aumento significativo a partir de 1994, em consequência dos desdobramentos do Plano Real. A securitização e o alongamento das dívidas dos agricultores, com o Programa de Revitalização de Cooperativas de Produção Agropecuária (RECOOP), voltado para o refinanciamento das dívidas do setor cooperativista e para o financiamento de capital de giro e de investimentos, também foram fundamentais para a garantia desse crescimento significativo. Entretanto, no período entre 2004 e 2006, verificou-se queda acentuada no Valor Bruto da Produção, o que deve estar intimamente associado à queda em cerca de $40 \%$ nos preços pagos aos produtores, concomitantemente a uma redução na produtividade. Contudo, nos últimos anos da série estudada, o Valor Bruto da Produção da mamona voltou a subir, o que pode ser atribuído ao aumento simultâ- 
neo na área colhida, na produtividade e nos preços pagos ao produtor. Através da aplicação do Modelo Shift-Share será possível verificar, com maior clareza, o peso dessas fontes de variação sobre o Valor Bruto da Produção da Mamona, na Figura 5, a seguir.

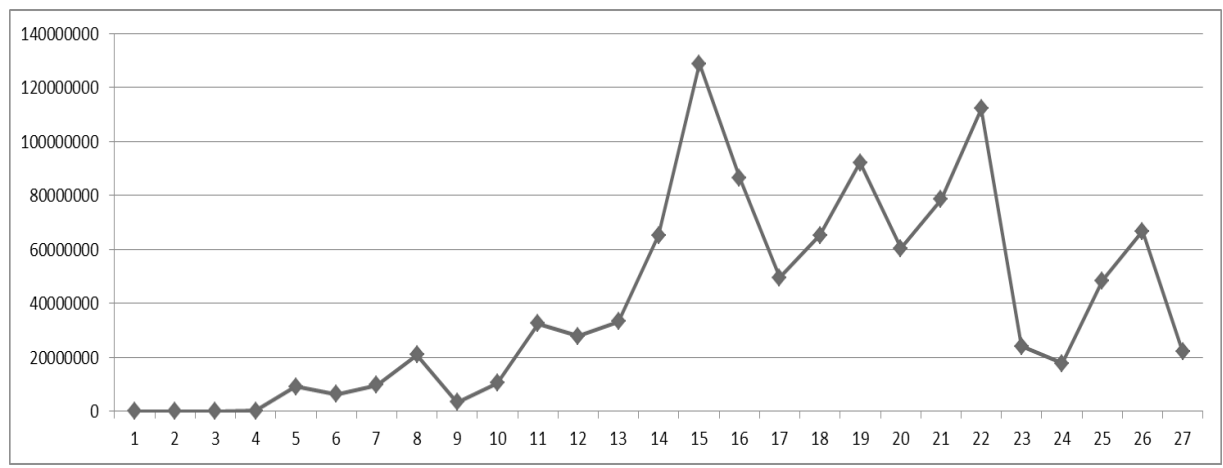

Figura 5. Evolução do Valor Bruto da Produção da mamona: Nordeste, 1990-2016

$(\mathrm{R} \$ 1.000,00)$.

Fonte: Pesquisa Agrícola Municipal do IBGE (BRASIL, 2010a).

\subsection{FONTES DE VARIAÇÃO DA PRODUÇÃO DE MAMONA}

A primeira aplicação do Modelo Shift-Share foi feita sobre variações entre o período $(t)$ e o período $(t-1)$. Nesse sentido, foi possível obter as fontes de variação do Valor Bruto da Produção da mamona a cada ano, conforme descrito na Tabela 2.

Tabela 2. Fontes de crescimento do Valor Bruto da Produção de mamona: Nordeste, 19902016 (ano base: $t-1$ )

(Continua)

\begin{tabular}{ccccc}
\hline Ano & $\begin{array}{c}\text { Efeito-Total } \\
\text { (\% a. a.) }\end{array}$ & $\begin{array}{c}\text { Efeito-Área } \\
\text { (\% a. a.) }\end{array}$ & $\begin{array}{c}\text { Efeito-Produtividade } \\
\text { (\% a. a.) }\end{array}$ & $\begin{array}{c}\text { Efeito-Preço } \\
\text { (\% a. a.) }\end{array}$ \\
\hline 1990 & - & - & - & - \\
1991 & 548,09 & $-18,55$ & 8,83 & 557,81 \\
1992 & 408,06 & $-24,35$ & 4,71 & 427,70 \\
1993 & $1.151,87$ & $-17,94$ & $-42,08$ & $1.211,89$ \\
1994 & $3.066,10$ & $-23,51$ & 64,36 & $3.025,25$ \\
1995 & $-29,74$ & $-28,89$ & $-12,57$ & 11,72 \\
\hline
\end{tabular}


(Conclusão)

\begin{tabular}{ccccc}
\hline Ano & $\begin{array}{c}\text { Efeito-Total } \\
\text { (\% a. a.) }\end{array}$ & $\begin{array}{c}\text { Efeito-Área } \\
\text { (\% a. a. })\end{array}$ & $\begin{array}{c}\text { Efeito-Produtividade } \\
\text { (\% a. a.) }\end{array}$ & $\begin{array}{c}\text { Efeito-Preço } \\
\text { (\% a. a.) }\end{array}$ \\
\hline 1996 & 50,63 & 60,72 & $-26,88$ & 16,78 \\
1997 & 115,66 & 26,78 & 110,58 & $-21,70$ \\
1998 & $-83,37$ & $-59,81$ & $-26,18$ & 2,61 \\
1999 & 204,64 & 64,67 & 49,16 & 90,81 \\
2000 & 208,45 & 78,73 & 132,10 & $-2,37$ \\
2001 & $-14,30$ & $-14,52$ & $-1,50$ & 1,72 \\
2002 & 18,86 & $-25,20$ & 16,55 & 27,52 \\
2003 & 96,07 & 12,90 & 0,01 & 83,16 \\
2004 & 97,51 & 28,09 & 39,30 & 30,12 \\
2005 & $-32,81$ & 33,99 & $-12,39$ & $-54,41$ \\
2006 & $-42,80$ & $-36,97$ & $-8,96$ & 3,12 \\
2007 & 31,95 & 9,62 & $-8,97$ & 31,30 \\
2008 & 41,34 & $-2,47$ & 31,71 & 12,09 \\
2009 & 62,98 & $-0,015$ & 0,00025 & 63 \\
2010 & 69,33 & $-0,0005$ & 0,0002 & 69,33 \\
2011 & 68,02 & $-0,00165$ & 0,000145 & 68,018 \\
2012 & 53,647 & $-0,0019$ & $-0,00029$ & 53,65 \\
2013 & 49,04 & $-0,003$ & $-0,0002$ & 49,048 \\
2014 & 52,655 & $-0,001$ & 0,00008 & 40,656 \\
2015 & 4,53 & $-0,000058$ & 0,0000057 & 0,584 \\
2016 & 40,58 & $-0,0035$ & & \\
\hline
\end{tabular}

Fonte: Elaboração própria.

Nesse sentido, algumas características da evolução do Valor Bruto da Produção da mamona devem ser levantadas. Primeiramente, é aparente o crescimento no valor da produção nos primeiros anos da série, entre 1990 e 1994 (só entre 1993 e 1994, o acréscimo foi de mais de 30 vezes), o que pode ser claramente explicado pela evolução do preço pago ao produtor no mesmo período, sendo assim a principal fonte de acréscimo. Em contrapartida, o efeito-área se mostrou sempre negativo nesse período, enquanto o efeito-produtividade sofreu oscilações. Em 1995, por sua vez, verificou-se a primeira queda no valor da produção da mamona na série 
estudada. Como verificado, esse decréscimo foi resultante principalmente do efeito-área negativo e, em menor grau, do efeito-produtividade também negativo. Apesar do efeito-preço ter se mostrado positivo, este não foi capaz de superar o péssimo desempenho das demais componentes naquele ano, com relação ao ano anterior.

Outros anos foram caracterizados por queda no Valor Bruto da Produção da mamona com relação ao ano anterior: em 1998, fortemente influenciado pelo efeito-área e, em menor grau, pelo efeito-produtividade; em 2001, influenciado quase que exclusivamente pelo efeito-área; em 2005, fortemente explicado pelo efeito-preço e, em menor grau, pelo efeito-produtividade; e em 2006, influenciado quase que exclusivamente pelo efeito-área e, em menor grau, pelo efeito-produtividade.

Por sua vez, os principais picos de acréscimo com relação ao ano anterior foram verificados nos seguintes anos: em 1994, como já comentado; em 1997, fortemente influenciado pelo efeito-produtividade e levemente pelo efeito-área; em 1999, explicado pelo efeito-preço e, em menor grau, pelo efeito-área e pelo efeito-produtividade; em 2000, explicado principalmente pelo efeito-área e pelo efeito-produtividade; em 2003, principalmente devido ao efeito-preço e, em menor escala, pelo efeito-área; e, em 2004, com participações semelhantes de todas as componentes.

Em 2008, verificou-se que o crescimento do valor da produção relativo ao ano anterior, correspondente a 41,3\%, deveu-se à contribuição de 31,7\% do efeito-produtividade, além dos 12,1\% do efeito-preço. Em contrapartida, houve uma consequência negativa por parte do efeito-área, ainda que de maneira leve, da ordem dos 2,5\%. Nos anos seguintes o valor da produção sofreu poucas oscilações, com exceção à grande divergência no preço em 2015. A partir de 2006 até o último ano da série, tiveram momentos negativos no efeito-área, devendo-se pela diminuição da produtividade, e de forma suave pelo decréscimo leve do preço.

Contudo, apesar do interesse em se verificar as fontes de crescimento e decréscimo quanto ao desempenho do ano $(t)$ com relação ao ano anterior, também se faz necessária uma análise de períodos específicos. Nesse sentido, apresenta-se a Tabela 3, que traz a participação das componentes área, produtividade e preço sobre fases distintas na série estudada. Assim, os cálculos levaram em consideração o primeiro ano de cada período como ano base. As taxas percentuais encontradas dizem respeito, portanto, à variação anual média (mesma ideia do coeficiente $r$ ) entre o ano final e o ano inicial de cada fase. 
Tabela 3. Fontes de crescimento do Valor Bruto da Produção de mamona: Nordeste, fases distintas de 1990-2016

\begin{tabular}{ccccc}
\hline Período & $\begin{array}{c}\text { Efeito-Total } \\
\text { (\% a. a.) }\end{array}$ & $\begin{array}{c}\text { Efeito-Área } \\
\text { (\% a. a.) }\end{array}$ & $\begin{array}{c}\text { Efeito-Produtividade } \\
\text { (\% a. a.) }\end{array}$ & $\begin{array}{c}\text { Efeito-Preço } \\
\text { (\% a. a.) }\end{array}$ \\
\hline $\begin{array}{c}\text { 1990-1994 } \\
\text { (base: } 1990)\end{array}$ & 968,83 & $-0,05$ & 0,00 & 968,87 \\
$\begin{array}{c}1995-1997 \\
\text { (base: } 1995)\end{array}$ & 80,24 & 37,03 & 40,66 & 2,55 \\
$\begin{array}{c}\text { 1998-2000 } \\
\text { (base: } 1998)\end{array}$ & 206,54 & 47,79 & 91,09 & 67,65 \\
$\begin{array}{c}\text { 2001-2004 } \\
\text { (base: } 2001)\end{array}$ & 66,35 & 1,50 & 11,87 & 52,97 \\
$\begin{array}{c}2004-2006 \\
\text { (base: } 2004)\end{array}$ & $-38,01$ & $-9,60$ & $-11,55$ & $-16,87$ \\
$\begin{array}{c}2006-2008 \\
\text { (base: } 2006)\end{array}$ & 36,56 & 2,92 & 9,79 & 23,85 \\
$\begin{array}{c}2008-2012 \\
\text { (base: } 2008 \text { ) }\end{array}$ & $-24,9$ & $-13,7$ & $-10,5$ & $-0,67$ \\
$\begin{array}{c}2012-2016 \\
\text { (base: } 2012)\end{array}$ & $-137,68$ & $-16,63$ & $-11,88$ & $-109,16$ \\
\hline
\end{tabular}

Fonte: Elaboração própria.

Como pode ser verificada, a fase de maior ascensão no Valor Bruto da Produção da mamona corresponde ao período 1990-1994, o que está quase que exclusivamente ligado ao efeito-preço. Entre 1995 e 1997, por sua vez, o crescimento se mostrou menos contundente, tendo como principais fontes o efeito-produtividade e o efeito-área. Um novo período de forte ascensão foi observado entre 1998 e 2000, dessa vez influenciada por todas as componentes, ainda que mais fortemente pelo efeito-produtividade. $\mathrm{O}$ ritmo de crescimento foi novamente menos intenso entre 2001 e 2004, período em que o efeito-preço se demonstrou mais importante dentre as demais componentes. Por sua vez, o único período de decréscimo consecutivo se deu entre 2004 e 2006, respondendo a variações negativas de todos os efeitos em escalas semelhantes. O último período analisado, entre 2006 e 2008, teve taxa anual média de crescimento equivalente a $36,6 \%$, com participação mais efetiva por parte do efeito-preço (em 23,8\%) e, em menor grau, por parte do efeito-produtividade (em 9,8\%) e do efeito-área (em 2,9\%).

Observa-se que, considerando a análise por fases distintas, o efeito-preço se 
destaca como principal fonte das variações do Valor Bruto da Produção da mamona, entre os anos de 1990 e 1998. Como verificado, sua contribuição se mostrou mais elevada em todos os períodos considerados, exceto nas fases de 1995 a 1997, quando teve ínfima participação; e entre 1998 e 2000, quando seu efeito só se mostrou inferior ao efeito-produtividade. Os períodos de 2008 a 2016 mostraram-se sempre em redução em relação aos períodos isolados anteriormente, sofrendo grande influência do efeito-preço. Percebe-se que os últimos períodos analisados sofrem oscilações decorrentes de possíveis abalos na estrutura política e econômica dos produtos comercializados devido à crise que assolou o país em diversos momentos desestruturando continuidade de políticas públicas dos governos e/ou reformas, em paralelo com situações de crise natural, com os abalos climáticos.

\section{CONCLUSÕES}

Os resultados do presente estudo apontaram para um melhor entendimento sobre as fontes de crescimento do Valor Bruto da Produção da mamona no Nordeste. Cabe ressaltar que esses resultados podem se estender praticamente ao valor da produção da mamona no Brasil, tendo em vista que em torno de $90 \%$ da produção nacional advém da região nordestina. Os resultados ainda podem ser replicados para o Estado da Bahia, visto que o Estado responde por cerca de $90 \%$ da produção da mamona no Nordeste.

No período em análise, o comportamento do Valor Bruto da Produção da mamona se caracterizou por oscilações, ora com fases de crescimento, ora com declínios. O maior pico foi apresentado no ano de 2004, quando o valor da produção chegou aos R\$ 128,7 milhões, resultado associado à implantação do Programa de Biodiesel do Governo Federal. No último ano da série, em 2008, o valor da produção alcançou R\$92,2 milhões, correspondente à produção de 108,3 mil toneladas de mamona em bagas. A produção é quase que exclusivamente voltada ao mercado nacional, e em 2011 a produção atinge significativamente outro pico de $\mathrm{R} \$ 112$ milhões.

Quanto à aplicação do Modelo Shift-Share, as seguintes conclusões podem ser elaboradas: i) entre 1990 e 1994, o efeito-preço foi responsável pelo forte crescimento no valor da produção nesse período; ii) em 1995, houve uma queda com 
relação a 1994, resultante principalmente pelo efeito-área; iii) entre 1995 e 1997, a nova fase de crescimento se deu em função do efeito-produtividade e do efeito-área; iv) em 1998, uma nova queda foi verificada com relação ao ano anterior, devido principalmente ao efeito-produtividade; v) entre 1998 e 2000, deu-se uma nova fase de forte crescimento, baseada primordialmente no efeito-produtividade, ainda que as demais componentes também tenham contribuído significativamente; vi) em 2001, o valor da produção novamente caiu com relação ao ano anterior, principalmente devido ao efeito-área; vii) entre 2001 e 2004, o crescimento no valor da produção foi influenciado pelo efeito-preço; viii) entre 2004 e 2006, deu-se a única fase de anos consecutivos com decréscimo no valor da produção, com influências de efeitos negativos em todas as componentes; ix) finalmente, entre 2006 e 2008, verificou-se nova fase de crescimento, associada principalmente ao efeito-preço.

Nesse sentido, percebe-se que as variações no Valor Bruto da Produção da mamona estão relacionadas principalmente com o efeito-preço. Contudo, o efeito-preço não se mostrou influente nas flutuações ocorridas nos seguintes anos: i) de 1995 a 1998, quando se destacou o efeito-área (exceto em 1997, quando o efeito-produtividade se mostrou contundente); ii) em 2000, com maior força por parte do efeito-produtividade e, em menor grau, do efeito-área; iii) em 2001, com forte contribuição do efeito-área; iv) e em 2006, destacando-se novamente o efeito-área. Em 2011, oscilações crescentes oriundas do efeito-área e em 2016 pelo efeito-preço influenciando na produção de forma reduzida.

Vale ainda ressaltar que, opostamente ao efeito-preço, o efeito-área se mostrou muitas vezes associado a uma influência de queda no Valor Bruto da produção da mamona, o que se relaciona com a tendência decrescente da área colhida observada no período em estudo. O efeito-produtividade, por vezes, também demonstrou influências negativas sobre o valor de produção, o que deve estar relacionado com o fato da ausência de rotação de culturas, causando um desgaste no solo cultivado ao longo do tempo. Referidas questões apontam para a necessidade de implantação de novas tecnologias para o cultivo da ricinocultura, propiciando uma melhoria na qualidade do produto e o consequente aumento no preço pago aos produtores.

Para tanto, é necessário atenção para organizar o sistema produtivo e a obtenção de insumos adequados, bem como solucionar os problemas com a oferta de 
crédito e de assistência técnica. Deve-se ainda notar que o mercado interno requer maior organização no sentido de ampliar o número de compradores e de agentes ligados à comercialização. Nesse sentido, é essencial que sejam estabelecidos relacionamentos entre os produtores da matéria-prima e os empresários da indústria de esmagamento, de modo que sejam respeitadas as necessidades de continuação de existência de cada um deles. É de fundamental importância, portanto, o comprometimento governamental (federal, estadual e municipal) e dos diversos agentes relacionados, no sentido de aplicar políticas adequadas, tendo em vista a importância socioeconômica da ricinocultura.

\section{REFERÊNCIAS}

ALBUQUERQUE, J. J. L.; PINHEIRO, A. A. P. Análise do desempenho agrícola de duas micro-regiões do sertão central (Ceará), através do modelo estrutural diferencial. Revista Ciência Agronômica, v. 10, n. 1, p. 99-101. Fortaleza: CCA/UFC, 1980.

ALMEIDA, C. M.; ALMEIDA NETO, J. A.; PIRES, M. M. A produção de mamona no Brasil e o PROBIODIESEL. In: I CONGRESSO BRASILEIRO DE MAMONA: ENERGIA E SUSTENTABILIDADE, 1., 2004. Anais [...] Campina Grande: EMBRAPA-Governo da Paraíba, 2004. 5p.

AMORIM, P. Q. R. Perspectiva histórica da cadeia da mamona e a introdução da produção de biodiesel no semiárido brasileiro sob o enfoque da teoria dos custos de transação. 2005. 95f. Monografia (Graduação em Economia). Piracicaba: ESALq-USP, 2005.

ARAÚJO, A. C.; CAMPOS, R. T. Análise da evolução do valor da produção de cacau no estado da Bahia. In: AGUILAR, D. R.; PINHO, J. B. (Ed.). O agronegócio brasileiro: desafios e perspectivas. Brasília: SOBER, 1998. v. 1, p. 1029-1039.

BAHIA. Secretaria da Indústria, Comércio e Turismo. Diagnóstico e oportunidades de investimentos: mamona. Salvador: SEBRAE, 1995. (Série Oleaginosas, v. 5.). 64p.

BIODIESELBR. Produção nacional de mamona. Disponível em: http://www.bio- 
dieselbr.com/plantas/mamona/producao-nacional-mamona.htm Acesso em: mar. 2010.

BRASIL. Empresa Brasileira de Pesquisa Agropecuária. Portal de informações sobre a mamona. Disponível em: http://www.cnpa.embrapa.br/produtos/mamona/ index.html. Acesso em: março, 2010b.

BRASIL. Presidência da República. Lei no 11.097, de 13 de janeiro de 2005. Disponível em: http://www.planalto.gov.br/ccivil/_Ato2004-2006/2005/Lei/L11097.htm Acesso em: mar. 2010.

CHIARANDA, M.; ANDRADE JUNIOR, A. M.; OLIVEIRA, G. T. A produção de biodiesel no Brasil e aspectos do PNPB. Piracicaba: GEEDES/ESALQ/USP, 2005. 32p.

CHIERICE, G. O.; CLARO NETO, S. Aplicação industrial do óleo. In: AZEVEDO, D. M. P.; LIMA, E. F. O agronegócio da mamona no Brasil. Brasília: EMBRAPA, 2001. p. 89-119.

COELHO, I. Avaliação das exportações tradicionais baianas: caso de sisal e mamona. 1979. 174f. Dissertação (Mestrado em Economia) - UFBA, Salvador, 1979.

FAO. Food and Agriculture Organization of the United Nations. Home page. Disponível em: http://www.fao.org/ Acesso em: mar. 2010.

FILGUEIRAS, G. C.; SANTOS, M. A. S.; IGREJA, A. C. M. Fontes de crescimento do valor bruto da produção de cacau no estado do Pará no período de 1980 a 2002. Belém: Banco da Amazônia, 2003. 14p. Disponível em: http://www.bancoamazonia.com.br/bancoamazonia2/institucional_biblioteca_artigos_economiaregional. asp. Acesso em: mar. 2010.

FILGUEIRAS, G. C.; SANTOS, M. A. S.; SANTANA, A. C.; HOMMA, A. K. O. Fontes de crescimento da produção de pimenta-do-reino no estado do Pará no período de 1979 a 2001. Belém: Banco da Amazônia, 2002. 14p. Disponível em: http://www. bancoamazonia.com.br/bancoamazonia2/institucional_biblioteca_artigos_economiaregional.asp. Acesso em: mar. 2010.

FREITAS, S. M.; FREDO, C. E. Biodiesel à base de óleo de mamona: algumas conside- 
rações. Informações Econômicas, v. 35, n. 1, p. 37-42, 2005.

KOURI, J.; SANTOS, R. F.; SANTOS, J. W. Evolução da cultura da mamona no Brasil. In: CONGRESSO BRASILEIRO DE MAMONA: ENERGIA E SUSTENTABILIDADE. Anais [...] Campina Grande: EMBRAPA-Governo da Paraíba, 2004. 6p.

MAGRINI, J. L.; CANEVER, M. D. O valor da produção da orizicultura gaúcha: componentes área, produtividade e preço. Revista Brasileira de Agrociência, v. 9, n. 1, p. 65-69, 2003.

PARK, K. H. Projeto Biodiesel e a inclusão social. In: CONGRESSO DA REDE BRASILEIRA DE TECNOLOGIA DO BIODIESEL: artigos técnicos e científicos, 1., 2006. Anais [...] Brasília: MCT-ABIPTI, 2006. p. 61-66.

PIRES, M. M.; ALVES, J. M.; NETO, J. A. A.; ALMEIDA, C. M.; SOUSA, G. S.; CRUZ, R. S.; MONTEIRO, R.; LOPES, B. S.; ROBRA, S. Biodiesel de mamona: uma avaliação econômica. In: CONGRESSO BRASILEIRO DE MAMONA: ENERGIA E SUSTENTABILIDADE, 1., 2004. Anais [...] Campina Grande: EMBRAPA-Governo da Paraíba, 2004. 5p.

PONCHIO, J. A. R. Relatório Final: Cadeia produtiva da mamona para biodiesel. Brasília: FAO, 2004.

SOUZA, P. M.; LIMA, J. E. Mudanças na composição da produção agrícola no Brasil, 1975-95. Revista Econômica do Nordeste, v. 33, n. 3, p. 632-659, 2002.

VIEIRA, R. M.; LIMA, E. F.; BATISTA, F. A. S. Diagnóstico e perspectivas da mamoneira no Brasil. In: REUNIÃO TEMÁTICA MATÉRIAS-PRIMAS OLEAGINOSAS NO BRASIL: DIAGNÓSTICO, PERSPECTIVAS E PRIORIDADES DE PESQUISA. Anais [...] Campina Grande: EMBRAPA-CNPA/MAA/ABIOVE, 1997. p. 139-150.

YOKOYAMA, L. P.; IGREJA, A. C. M. Principais lavouras da região centro-oeste: variações no período 1975-1987. Revista Pesquisa Agropecuária Brasileira, v. 27, n. 5, p. $727-736,1992$. 